\title{
Design Diagrams for the Analysis of Active Pressure on Retaining Walls with the Effect of Line Surcharge
}

\author{
Mojtaba Ahmadabadi and Mohammad Karim Faghirizadeh \\ Shiraz Art Institute of Higher Education, Shiraz, Iran \\ Correspondence should be addressed to Mohammad Karim Faghirizadeh; faghirizadeh@gmail.com
}

Received 2 November 2016; Revised 15 February 2017; Accepted 5 March 2017; Published 2 May 2017

Academic Editor: Pier Paolo Rossi

Copyright (c) 2017 Mojtaba Ahmadabadi and Mohammad Karim Faghirizadeh. This is an open access article distributed under the Creative Commons Attribution License, which permits unrestricted use, distribution, and reproduction in any medium, provided the original work is properly cited.

\begin{abstract}
In this study, a formulation has been proposed to calculate the pressure on wall and determine the angle of failure wedge based on limit equilibrium method. The mentioned formulation is capable of calculating active pressure coefficient, culmination of forces in failure surface, and pressure distribution on wall with the effect of line surcharge. In addition, based on the proposed method, a simple formula has been proposed to calculate the angle of failure wedge by the effect of surcharge. Moreover, the proposed approach has the advantage of taking into account the effect of surcharge on elastoplastic environment by considering the parameters of soil and determining the extent to which the surcharge is effective in pressure distribution on the wall. However, in most previous methods and specifications, resultant lateral pressure from surcharge in elastic environment had been considered. Finally, based on the obtained results, the design diagrams for different soils and different surcharges have been proposed. According to these diagrams, pressure on wall, pressure distribution on wall, and angle of failure wedge will easily be achieved. Also, a computer program has been written in MATLAB software environment. Using the results of these codes, the pressure on wall with the effect of surcharge, the angle of failure wedge, and pressure distribution on wall will be determined.
\end{abstract}

\section{Introduction}

The calculation of active soil pressure on retaining walls is of fundamental issues in foundation engineering. It is typically examined using the theory proposed by Coulomb [1] or Rankine theory [2]. On the other hand, active pressure is influenced by external loads affecting the soil behind the wall. In order to calculate the resultant lateral pressure on retaining walls caused by surcharge, Boussinesq method [3] is usually used that assumes a homogeneous and elastic behavior for soil. On the other hand, referring to the difference between the results of elastic methods by Boussinesq [3], Das [4] proposed equations with the assumption of elastic behavior to calculate the surcharge with actual values.

Gerber [5] and Spangler [6] examined the effect of surcharge on lateral pressure on retaining wall caused by a concentrated load using large-scale tests. The principles of the theory of elasticity to study the effects of line surcharge were initially used by Misra [7] and for strip surcharge by Jarquio [8]. In addition, Motta [9] offered a method for extensive uniform surcharges using developed Coulomb formulation and calculated active pressure on wall with the effect of surcharge according to the angle of failure wedge.

Seismic stability of retaining walls due to the effect of surcharge was studied by Caltabino et al. [10]. The researchers considered the effect of earthquake as quasi-static based on the method presented by Okabe [11] and Mononobe and Matsuo [12].

Using experimental results, Georgiadis and Anagnostopoulos [13] compared the result of pressure on shields under surcharge with those of different methods, including elastic stress distribution, and approximation of 45-degree slope, as well as the results of Coulomb method. As a result, elastic approach has a significant difference with real values. Kim and Barker [14] studied the impact of live surcharge caused by traffic load on retaining walls. The researchers proposed an analytical approach to calculate horizontal active pressure on retaining wall using equivalent bending moment method. 
Using the theory of Coulomb, Greco [15-18] investigated the effect of strip surcharge on active pressure on nonreinforced retaining walls and presented an analytical method for the calculation of pressure and the resultant effect point. AASHTO [19] and US Army Crops [20] specifications proposed an analytical method for calculating resultant lateral earth pressure caused by surcharge according to the type of surcharge incurred on the wall. Cheng [21] presented lateral pressure coefficient in seismic state for cohesive-friction soils and $q$ surcharges.

Basha and Basudhar [22] examined the stability of reinforced soil structures under seismic conditions using limit equilibrium method and assuming logarithmic spiral wedge failure. The researchers imposed seismic acceleration on reinforced soil structures using quasi-static method.

Ghanbari and Taheri [23] calculated the pressure on wall and reinforced force with the effect of surcharge on reinforced soil walls, under the assumption of Ahmadabadi and Ghanbari [24]. The results for changes in the angle of failure wedge with the size of the surcharge suggest that increasing the amount of surcharge will result in an increase in the angle of failure wedge; however, by changing the distance of the surcharge from the wall, the angle of failure wedge does not change any more. The results of their research indicate that with increasing the distance of surcharge from the wall, the lateral pressure of soil will be reduced and when it is out of the angle of failure wedge, it has no effect on active earth pressure.

In this paper, a simple solution has been presented to calculate active pressure on wall with effect of line surcharge using limit equilibrium method. In the previously proposed methods, either the effect of friction angle between soil and wall was neglected or complex and lengthy solutions were required. The primary objective of the research was to develop a simple method based on limit equilibrium that can calculate the angle of failure wedge and force distribution on wall with the effect of surcharge. Then the effect of angle of internal friction angle, the amount of line surcharge, the distance of line surcharge from the wall, and the angle of internal friction of soil will be discussed.

\section{Formulation for the Calculation of Pressure on Retaining Walls with the Effect of Line Surcharge}

According to Figure 1, a retaining wall where $\delta$ is the angle of internal friction between soil and wall will be considered. If the hypothetical angle of failure wedge forms the angle $\beta$ with the horizon, according to Figure 2, the angle which calculates the greatest amount of pressure on the wall with the line surcharge can be shown with $\beta_{3}$ and without the surcharge, it can be shown with $\beta_{1}$. To achieve the desired formulation, the following assumptions can be considered:

(1) The failure surface is considered as a page.

(2) The analysis is based on the limit equilibrium method.

(3) The failure surface passes from the wall.

(4) The soil mass is considered homogeneous.

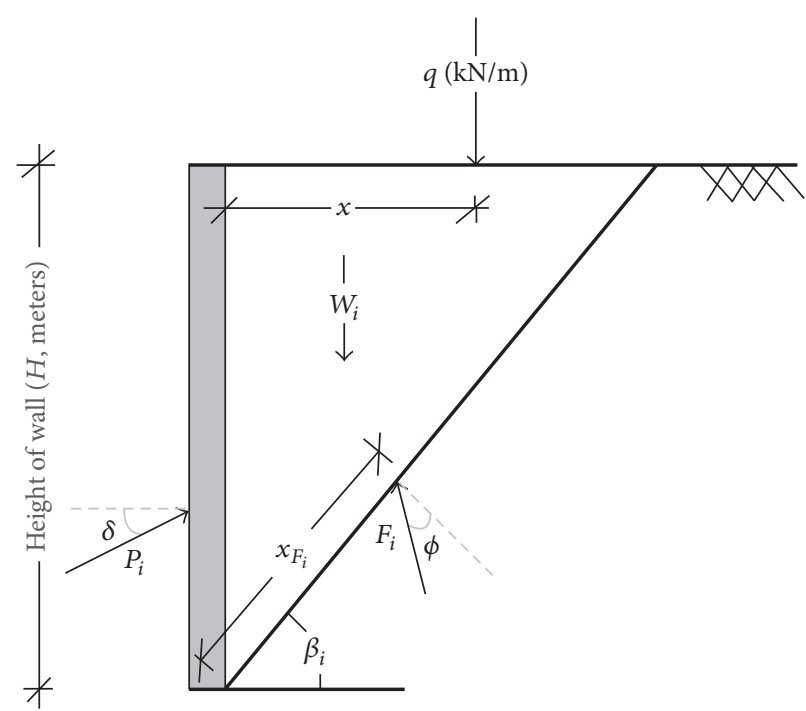

FIGURE 1: The equilibrium of forces in the $i$ th failure wedge.

(5) The behavioral model intended for cohesive soil is elastoplastic model of Coulomb.

According to Figure 1, with the line surcharge, equilibrium equations for a hypothetical failure wedge can be written as follows:

$$
\begin{aligned}
& \sum F_{x_{i}}=0 \longrightarrow \\
& P_{i} \cos \delta+F_{i} \sin \varphi \cos \beta_{i}-F_{i} \cos \varphi \sin \beta_{i}=0, \\
& \sum F_{y_{i}}=0 \longrightarrow \\
& F_{i} \cos \varphi \cos \beta_{i}+F_{i} \sin \varphi \sin \beta_{i}+P_{i} \sin \delta-W_{i}-q=0, \\
& \sum M_{o_{i}}=0 \longrightarrow \\
& -\frac{P_{i} H}{3} \cos \delta-\frac{W_{i} H}{3 \tan \beta_{i}}+F_{i} \cdot x_{F_{i}} \cos \varphi-q \cdot x=0 .
\end{aligned}
$$

By solving the three equations for each experimental wedge, $P_{i}, F_{i}$, and $x_{F}$ for the $i$ th failure wedge $\left(\beta_{i}\right)$ are obtained. Now, in the proposed formulation in order to determine the angle of failure wedge, the amount of active pressure on wall is calculated for different angles of failure wedge; then the angle that gives maximum active pressure is recorded as the angle of failure wedge, where $P_{\mathrm{a}}$ is the active soil pressure without surcharge with $\beta_{1}, P_{\text {as }}$ is the active soil pressure with the effect of line surcharge with $\beta_{3}$, and $P_{\mathrm{aq}}$ is the added pressure on wall under line surcharge.

$$
\vec{P}_{\mathrm{as}}=\vec{P}_{\mathrm{a}}+\vec{P}_{\mathrm{aq}}
$$

Given the distance of surcharge from the wall, in order to calculate the pressure on wall $\left(P_{i}\right)$, three modes are considered. 


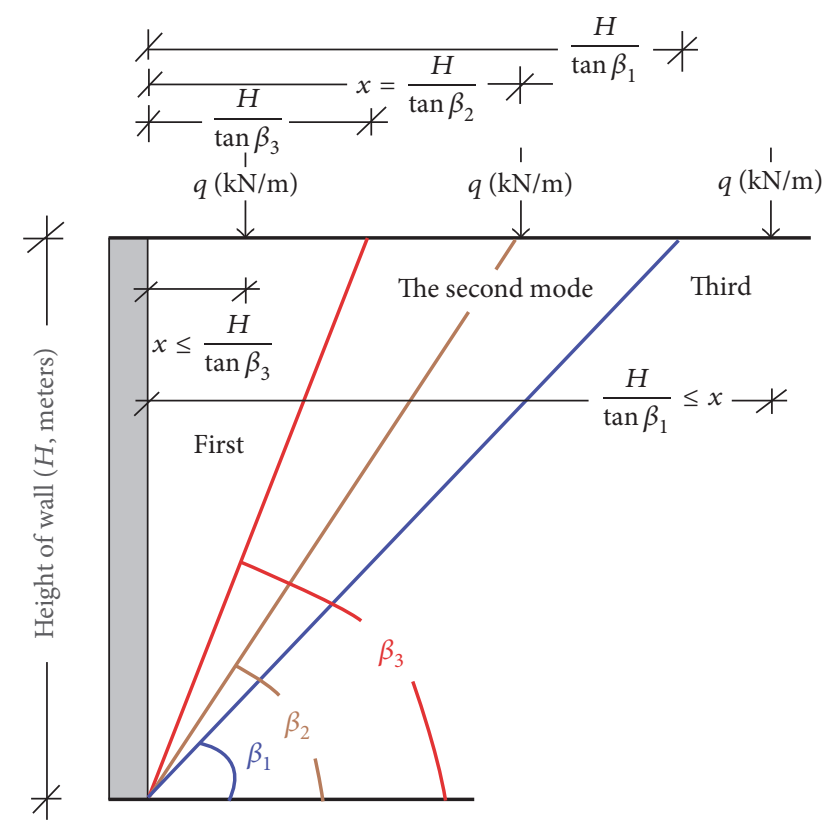

FIGURE 2: The distance of line surcharge from the wall in three different modes.

First Mode. If the distance of line surcharge from the wall is less than $x \leq H / \tan \beta_{3}$, then the active pressure on wall is obtained according to (2).

$$
x \leq \frac{H}{\tan \beta_{3}} \longrightarrow P=P_{\mathrm{as}}=P_{\mathrm{a}_{\text {surcharge }}} .
$$

Second Mode. If the distance of line surcharge equals the amount of $H / \tan \beta_{3} \leq x \leq H / \tan \beta_{1}$, then by substituting the angle $\beta_{2}$ in (1), the amount of pressure on the wall can be obtained according to

$$
\begin{aligned}
\beta_{2} & =\operatorname{Arctan} \frac{H}{x}, \\
\frac{H}{\tan \beta_{3}} & \leq x \leq \frac{H}{\tan \beta_{1}} \longrightarrow P=P_{\beta_{2}} \geq P_{\mathrm{a}} .
\end{aligned}
$$

Third. If the distance of the line surcharge is greater than $H / \tan \beta_{1}$, it states that the line surcharge on the wall has no effect and to calculate the pressure on wall, the amount of surcharge in (1) can be considered zero and present it as (6).

$$
\frac{H}{\tan \beta_{1}} \leq x \rightarrow P=P_{\mathrm{a}} .
$$

Now three types of active earth pressure coefficient can be defined as follows:

$$
\begin{aligned}
K_{\mathrm{a}} & =\frac{P_{\mathrm{a}}}{(1 / 2) \gamma H^{2}}, \\
K_{\mathrm{as}} & =\frac{P_{\mathrm{as}}}{(1 / 2) \gamma H^{2}},
\end{aligned}
$$

TABLE 1: The features of the sample wall in the analyses with the effect of line surcharge.

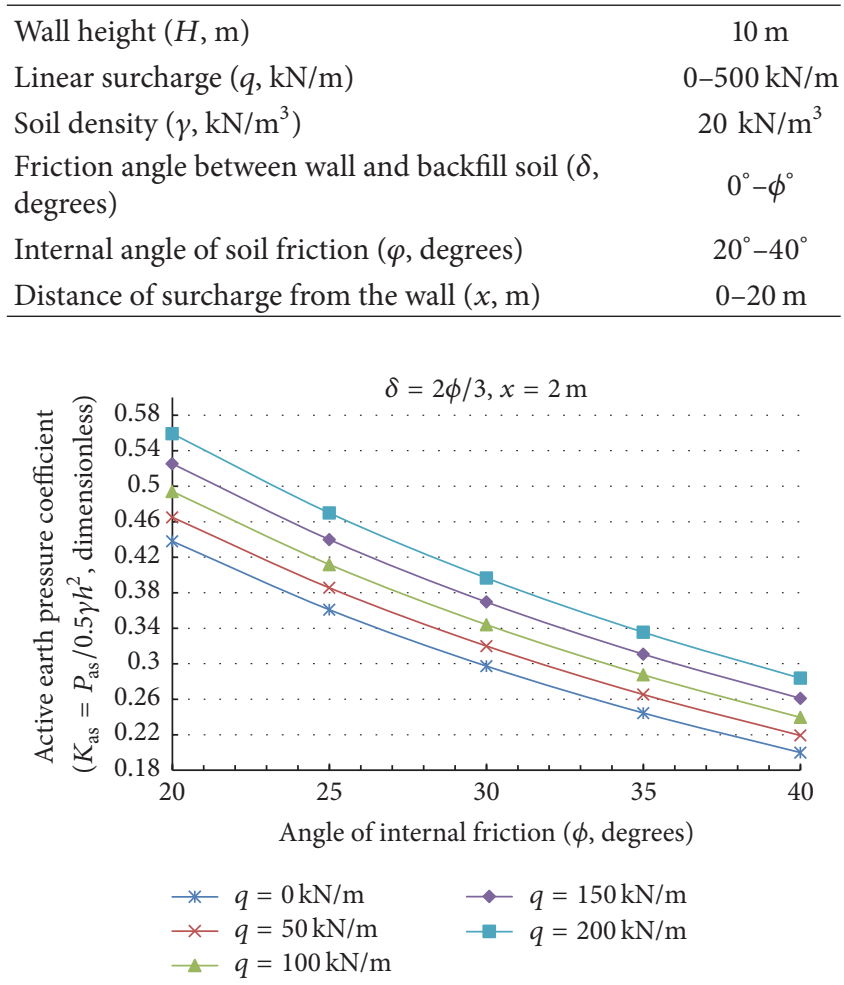

FIGURE 3: Changes in active pressure coefficient $\left(K_{\mathrm{as}}\right)$ against changes in the angle of internal soil friction for different amounts of line surcharge.

$$
K_{\mathrm{aq}}=\frac{P_{\mathrm{aq}}}{(1 / 2) \gamma H^{2}} .
$$

\section{The Evaluation of the Results of the Proposed Method with the Effect of Line Surcharge}

The proposed formulation has the ability to calculate the active pressure on wall, angle of failure wedge, and pressure distribution on wall for a variety of soil features. For this purpose, a sample retaining wall is intended whose features can be seen in Table 1 . In addition, the results of analyses carried out on the wall are discussed.

First, for one retaining wall, active pressure coefficient changes against the change in the angle of internal friction angle are examined by comparing different amounts of line surcharge. In order to provide dimensionless design diagram, active pressure coefficient $\left(K_{\mathrm{as}}\right)$ is used. As Figure 3 shows, an increase in the angle of soil internal friction of the soil reduces the coefficient of $K_{\mathrm{as}}$ nonlinearly. Also, an increase in the line surcharge increases the active soil pressure and ultimately increases $K_{\mathrm{as}}$ coefficient.

According to Figure 4, increasing the friction angle between soil and wall reduces the coefficient of $K_{\text {as }}$ 


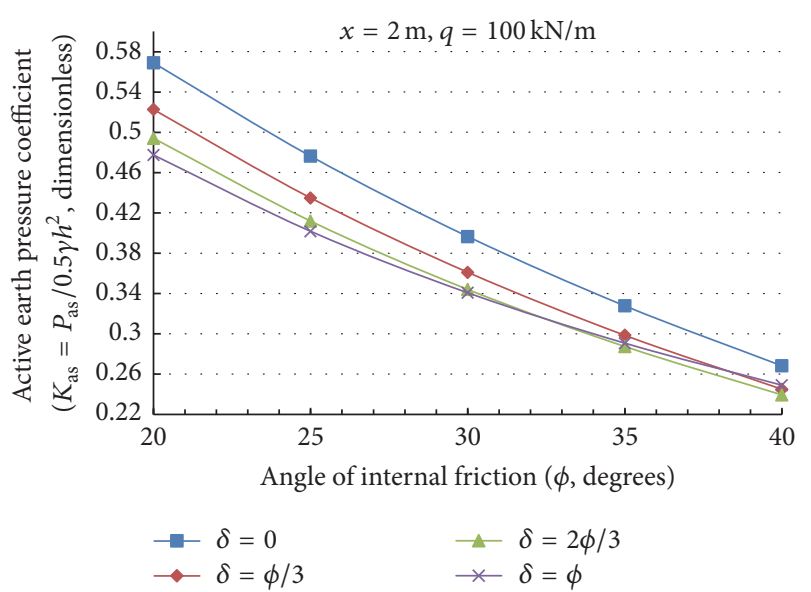

Figure 4: Changes in active pressure coefficient $\left(K_{\mathrm{as}}\right)$ against changes in the angle of internal soil friction for different amounts of friction angle between soil and wall.

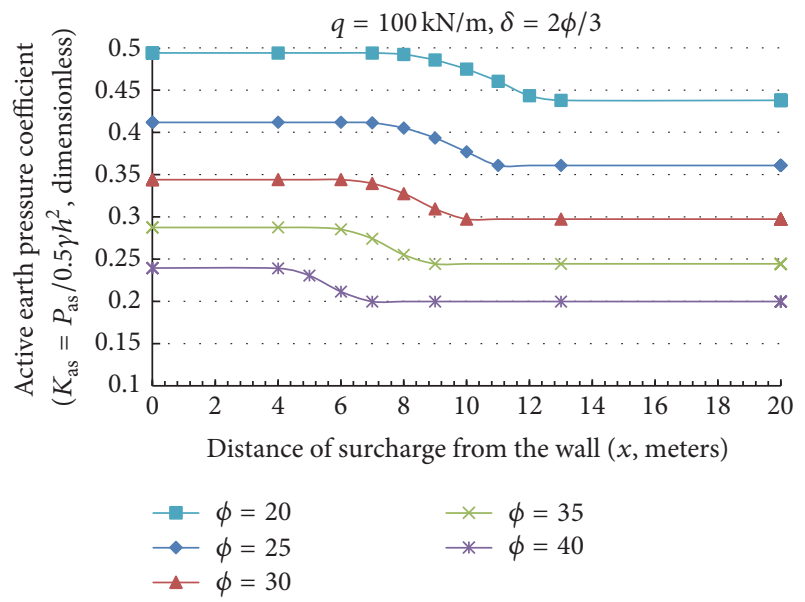

FIGURE 5: Changes in active pressure coefficient $\left(K_{\mathrm{as}}\right)$ against changes in the distance of surcharge from wall for different amounts of the angle of internal soil friction.

nonlinearly. This trend changes in $\phi$ larger than $35^{\circ}$ and $\delta$ larger than $2 \phi / 3$.

In Figures 5 and 6, active pressure coefficient $\left(K_{\mathrm{as}}\right)$ is plotted against the change in distance of discharge from the wall. With increasing the distance of surcharge from the wall, the pressure on wall is reduced. In Figure 5, the changes for surcharge $100 \mathrm{kN} / \mathrm{m}$ and in Figure 6 the changes for surcharge $200 \mathrm{kN} / \mathrm{m}$ are drawn. These changes always start from a maximum and end at a minimum level. For example, in $\phi=$ 20 , active pressure coefficient is always fluctuating between 0.43 and 0.49 . By an increase in the angle of internal friction of soil, the maximum distance of surcharge is reduced. For example, in $\phi=20$, maximum distance of surcharge reduces to 7 meters and in $\phi=40$, this amount is reduced to 4 meters.

In Figure 7 , active pressure coefficient $\left(K_{\mathrm{as}}\right)$ is plotted against changes in the angle of internal friction. These diagrams indicate the surface where active pressure coefficient changes according to the distance of the surcharge. The lower

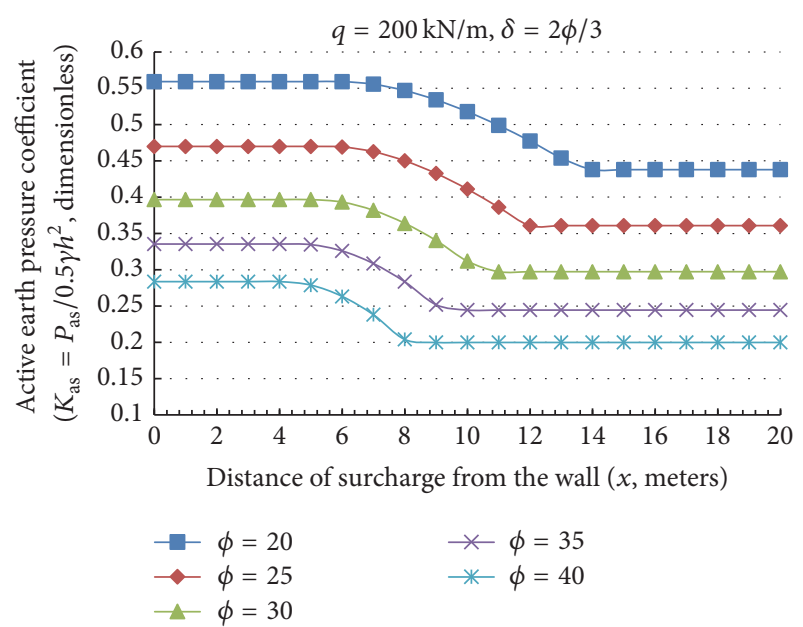

FIgURE 6: Changes in active pressure coefficient $\left(K_{\mathrm{as}}\right)$ against changes in the distance of surcharge from wall for different amounts of internal soil friction.

limit in each diagram states the minimum active pressure coefficient in the minimum distance of surcharge; however, the upper limit shows the maximum coefficient of active earth pressure on the wall in the maximum distance of surcharge. The diagrams are plotted for four values of line surcharge and for other values, interpolation can be used.

\section{Determination of the Angle of Failure Wedge with the Effect of Line Surcharge}

The angle that gives maximum active pressure is recorded as the angle of failure wedge. In Figure 8 changes in the angle of failure wedge against changes in the angle of internal friction of soil are plotted. Increased line surcharge and internal friction angle increase the angle of the failure wedge. To calculate the angle of failure wedge, the following proposed formulas can be used:

$$
\begin{aligned}
& \text { if } \cdots q=0 \frac{\mathrm{kN}}{\mathrm{m}^{2}} \Longrightarrow \beta=0.6 \varphi+38, \\
& \text { if } \cdots q=100 \frac{\mathrm{kN}}{\mathrm{m}^{2}} \Longrightarrow \beta=0.54 \varphi+43.2, \\
& \text { if } \cdots q=200 \frac{\mathrm{kN}}{\mathrm{m}^{2}} \Longrightarrow \beta=0.44 \varphi+50 .
\end{aligned}
$$

In general, this equation can be used to calculate the angle of failure wedge.

$$
\beta=-\frac{q \varphi}{7 \pi}+\frac{108 \varphi}{\pi}+\frac{q}{5 \pi}+12 \pi
$$

\section{Distribution of Stress to the Walls with the Effect of Line Surcharge}

In Figures 9 and 10, stress distribution is plotted for different values of the angle of internal friction. In Figure 9, total stress distribution, which includes earth pressure and the 

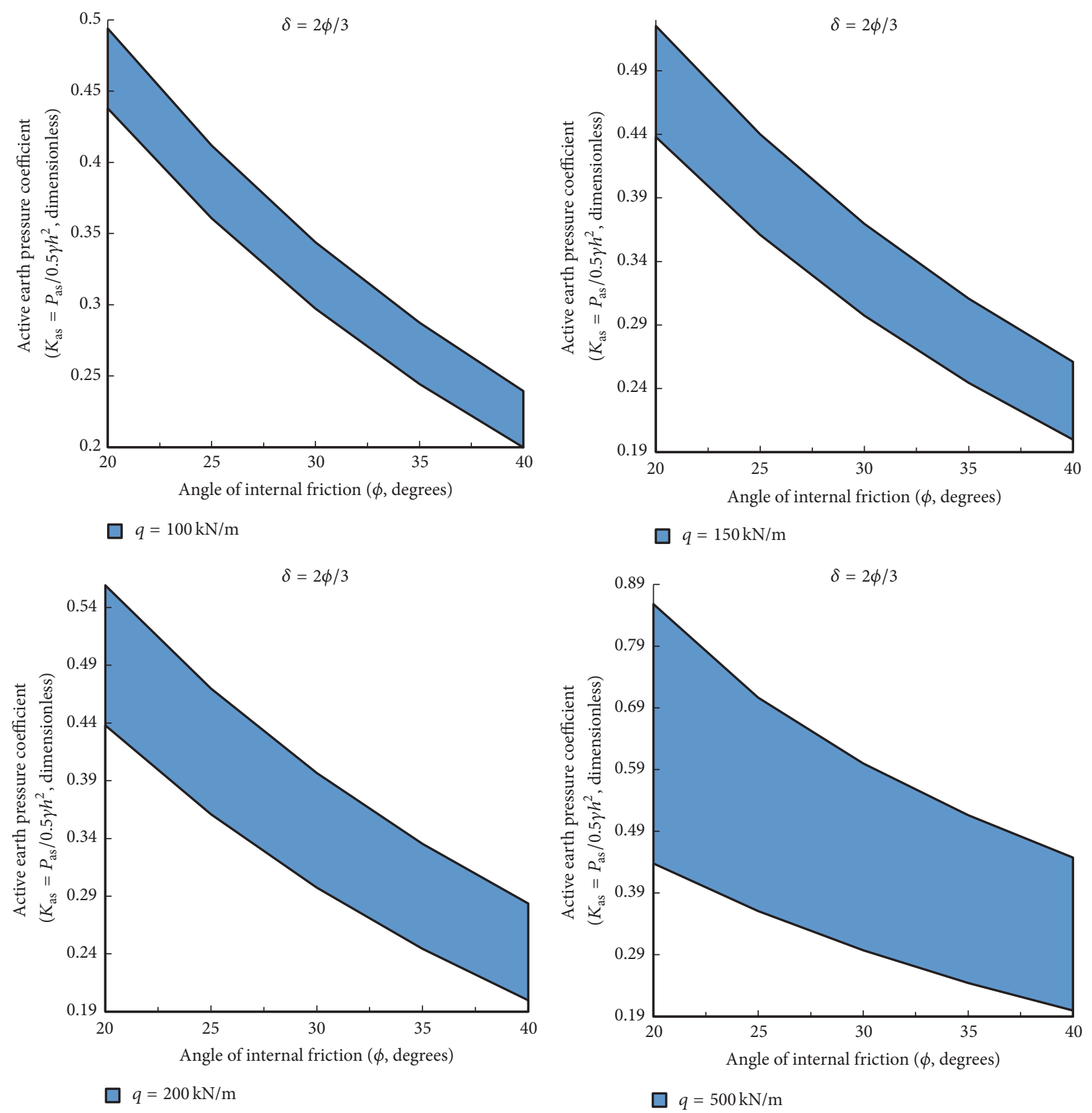

FIGURE 7: The changes of active pressure coefficient $\left(K_{\mathrm{as}}\right)$ against changes in the angle of internal friction for the distance of surcharge from the wall.

effect of surcharge, is drawn. By calculating the area under the diagram, the total pressure on wall $\left(P_{\mathrm{as}}\right)$ can be obtained. In Figure 10, lateral pressure distribution from the surcharge is plotted. By calculating the area under the diagram, the pressure from the surcharge $\left(P_{\mathrm{aq}}\right)$ can be obtained. Increased internal friction angle always reduces the stress distribution.

In Figures 11-13, stress distribution with changes in line surcharge is plotted. In Figures 11 and 12, the total pressure distribution for two values of $\phi=30$ and $\phi=40$ is drawn. In Figure 13, resultant lateral pressure distribution from the surcharge for different values of $0 \mathrm{kN} / \mathrm{m}$ to $200 \mathrm{kN} / \mathrm{m}$ is plotted. Increased line surcharge increases total stress distribution and resultant lateral pressure distribution from the surcharge.

\section{Comparison of the Results of the Proposed Method with the Results of Other Studies and Specifications}

In Table 2, the results of the proposed method for retaining wall with the effect of line surcharge have been compared with the results of Ghanbari and Taheri [23] and Motta [9] on equal terms. Results are intended in three modes of surcharge, that is, 20,50 , and $100(\mathrm{kN} / \mathrm{m})$, and for two internal friction angles. 


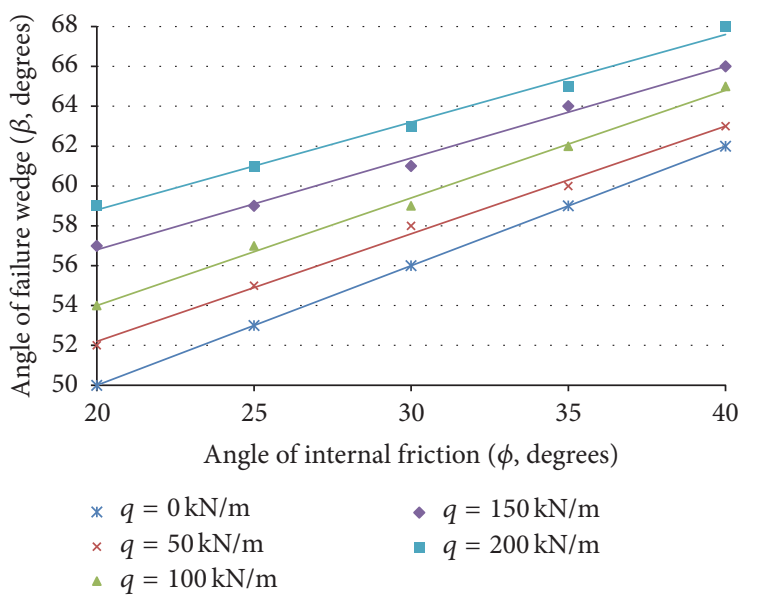

FIGURE 8: Changes in the angle of failure wedge against changes in internal friction angle of soil for different values of line surcharge.

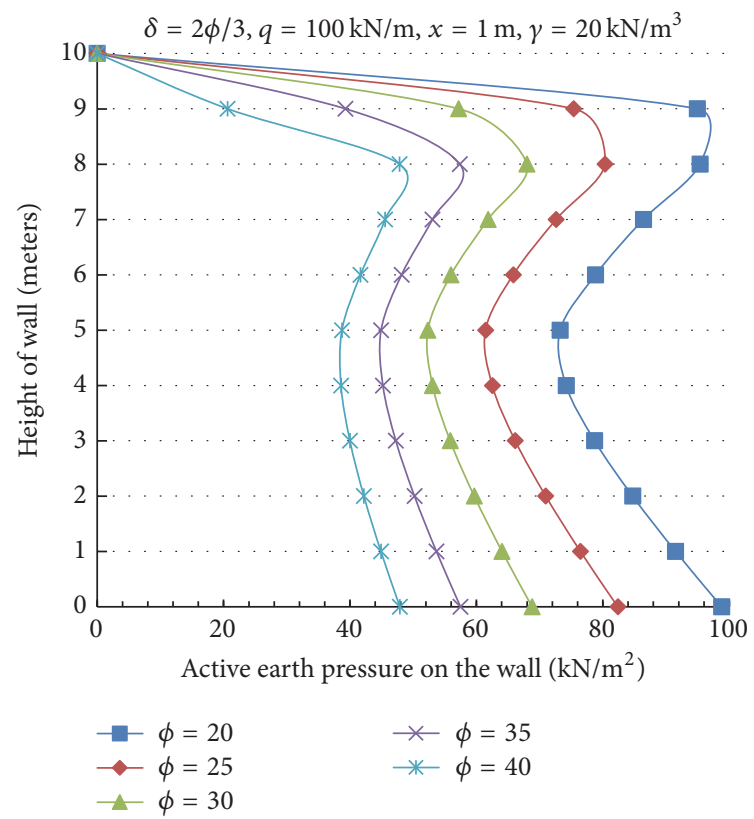

Figure 9: Total active pressure distribution on the wall for different values of the angle of internal friction.

Also in Table 3, the results of the proposed method have been evaluated with different specifications. In the specifications, soil parameters have not been considered and have been studied in an elastic mode; however, in the proposed method, soil parameters such as internal friction angle and the angle of friction between soil and wall have been taken into account. In Figure 14, resultant lateral pressure distribution from the surcharge has been plotted for the proposed approach, Das [4] elastic method, and AASHTO [19] specification. The stress distribution has been obtained with the assumption of an elastoplastic behavior and is somewhat different from stress distribution on Das [4] method and AASHTO [19] specification where the assumption of elastic behavior is used.

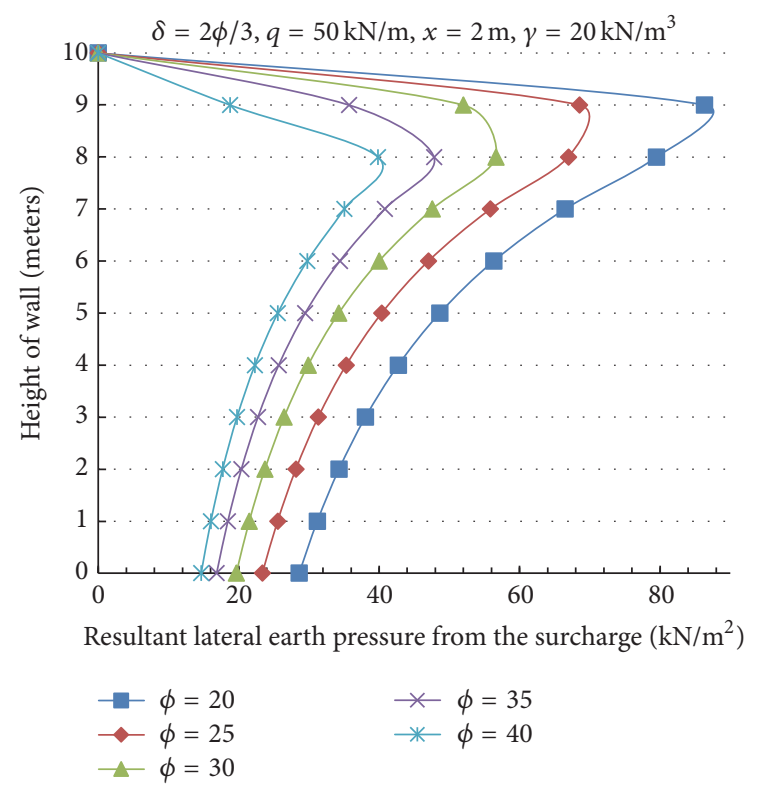

FIGURE 10: Resultant lateral earth pressure from the surcharge for different values of the angle of internal friction.

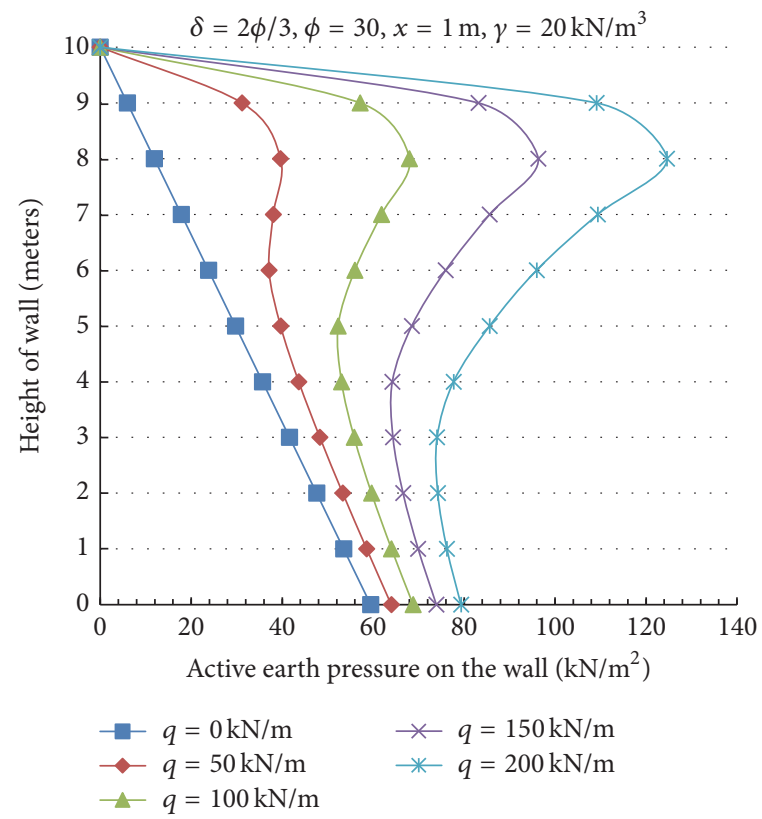

FIgURE 11: The total active pressure distribution on the wall for different values of line surcharge for $\phi=30$.

\section{Conclusions}

Based on the studies presented in this study, the following results can be extracted:

(1) For the retaining wall with the effect of line surcharge, a formulation has been proposed which contains $3 n$ equations and $3 n$ variables and using it, the coefficient of active pressure, angle of failure wedge, and the effect of the resultant forces at the failure surface with 
TABLE 2: Comparison of the results of the proposed method with Ghanbari and Taheri [23] and Motta [9].

\begin{tabular}{|c|c|c|c|c|c|c|}
\hline \multicolumn{7}{|c|}{$x=4 \mathrm{~m}, H=10 \mathrm{~m}, \delta=10^{\circ}, \gamma=20 \mathrm{kN} / \mathrm{m}^{3}$} \\
\hline & \multicolumn{3}{|c|}{$\phi=20^{\circ}$} & \multicolumn{3}{|c|}{$\phi=30^{\circ}$} \\
\hline & Proposed method & $\begin{array}{c}\text { Ghanbari and Taheri } \\
{[23]}\end{array}$ & $\begin{array}{c}\text { Motta } \\
{[9]}\end{array}$ & Proposed method & $\begin{array}{c}\text { Ghanbari and Taheri } \\
{[23]}\end{array}$ & $\begin{array}{c}\text { Motta } \\
\text { [9] }\end{array}$ \\
\hline \multicolumn{7}{|c|}{$q=20(\mathrm{kN} / \mathrm{m})$} \\
\hline$P_{\text {as }}$ & 457.96 & 457.5 & 463.5 & 318.34 & 315.08 & 318.9 \\
\hline$\beta$ & 52 & 51.9 & 51.4 & 59 & 57.2 & 57.3 \\
\hline \multicolumn{7}{|c|}{$q=50(\mathrm{kN} / \mathrm{m})$} \\
\hline$P_{\text {as }}$ & 475.44 & 472.4 & 488.9 & 333.80 & 321.7 & 334.9 \\
\hline$\beta$ & 53 & 53.3 & 52.1 & 60 & 59.7 & 58.1 \\
\hline \multicolumn{7}{|c|}{$q=100(\mathrm{kN} / \mathrm{m})$} \\
\hline$P_{\text {as }}$ & 506.50 & 491.4 & 531.5 & 361.04 & 334.7 & 361.6 \\
\hline$\beta$ & 56 & 55.7 & 52.9 & 62 & 61.6 & 59 \\
\hline
\end{tabular}

TABLE 3: Comparison of the results of the proposed method with Ghanbari and Taheri [23] and specifications (1994).

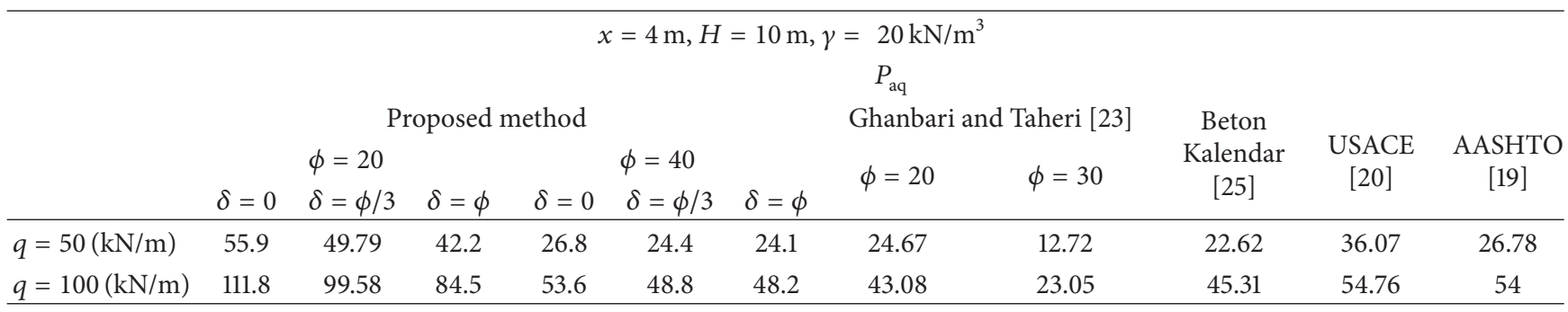

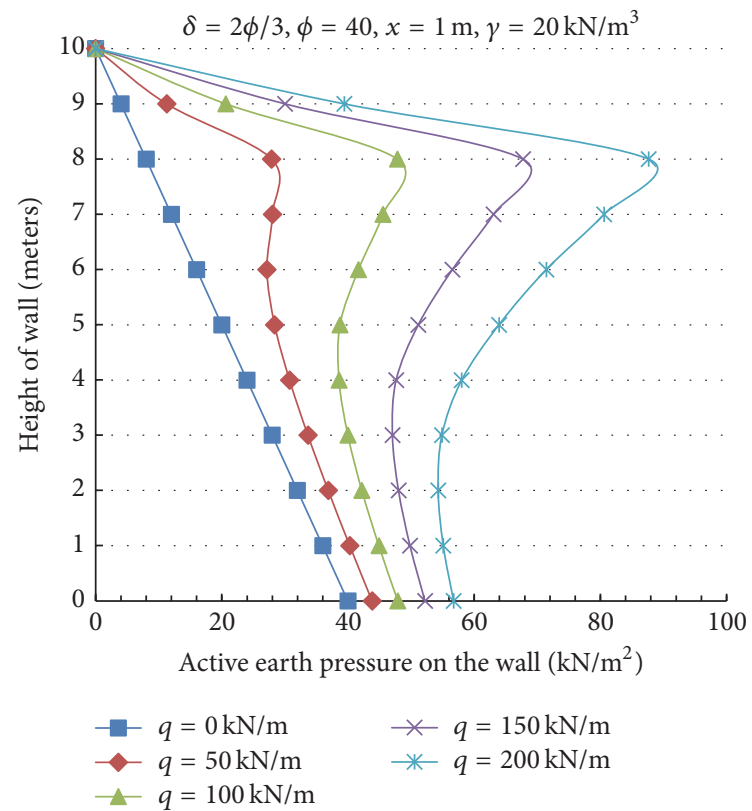

FIGURE 12: The total active pressure distribution on the wall for different values of line surcharge for $\phi=40$.

the effect of surcharge are obtained. The proposed method has also the advantage of plotting the pressure on wall and resultant lateral pressure distribution with the effect of line surcharge. Finally, three types of

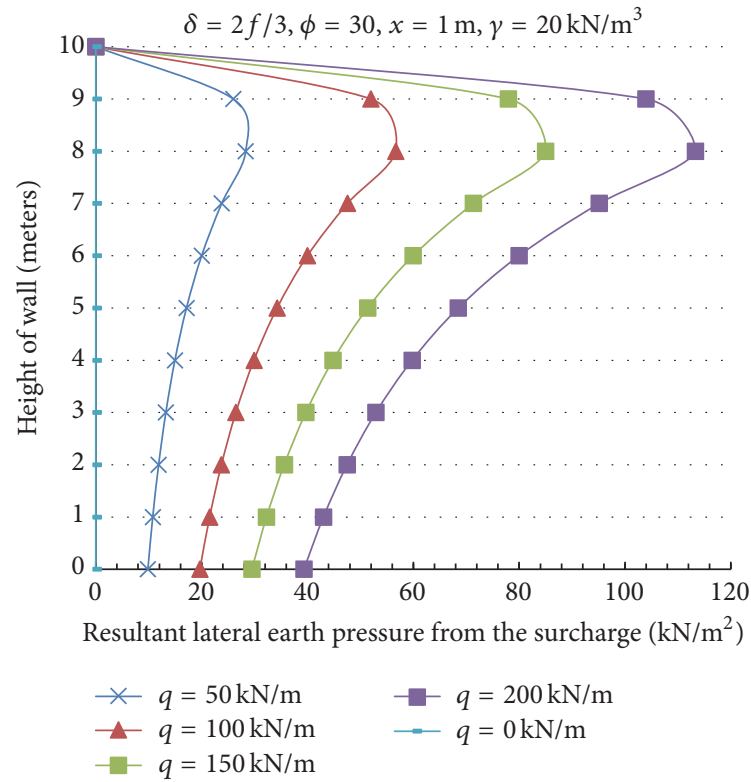

FIGURE 13: Resultant lateral earth pressure distribution for different values of line surcharge.

active earth pressure coefficient, $K_{\mathrm{as}}$ and $K_{\mathrm{aq}}$ and $K_{\mathrm{a}}$, can be defined.

(2) The results of the proposed method for retaining wall with the effect of line surcharge have been compared with the results of Ghanbari and Taheri [23] and 


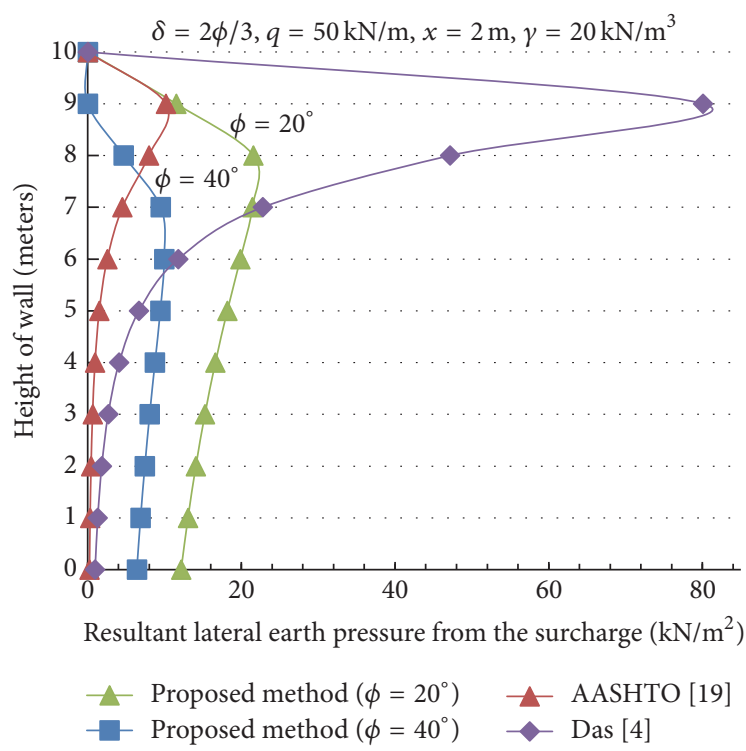

FIGURE 14: Resultant lateral earth pressure from the surcharge for the proposed method and AASHTO [19] and Das [4].

Motta [9], and AASHTO [19], USACE [20], and Beton Kalendar [25] specifications. The stress distribution has been obtained with the assumption of an elastoplastic behavior and is somewhat different from stress distribution on Das [4] method and AASHTO [19] specification where the assumption of elastic behavior is used.

(3) The proposed method is able to calculate the angle of the failure wedge with the effect of line surcharge. In addition, a formula has been proposed for calculating the angle of failure wedge with the effect of line surcharge. The conclusion was drawn that increased internal friction angle and line surcharge will result in the angle of failure wedge.

(4) In the research presented, a series of graphs has been applied according to which active pressure coefficient with the effect of line surcharge can be calculated without any analysis and can be used in implementations. These diagrams are dimensionless and using them, the areas where the surcharge is effective in the pressure distribution on wall can be determined.

(5) These diagrams indicate the surface where active pressure coefficient changes according to the distance of the surcharge. The lower limit in each diagram states the minimum active pressure coefficient in the maximum distance of surcharge; however, the upper limit shows the maximum coefficient of active earth pressure on the wall in the maximum distance of surcharge. The diagrams are plotted for four values of line surcharge and for other values, interpolation can be used.

(6) In this study, the effect of soil properties and surcharge on the amount of active pressure coefficient has been investigated and the conclusion was that increasing the angle of internal friction and the angle of friction between soil and wall and the distance of the surcharge from the wall will reduce the coefficient of active pressure; however, with increasing the line surcharge, the value of the coefficient of active pressure will increase. Moreover, increasing the angle of internal friction will reduce the stress distribution and resultant stress pressure on wall with the effect of line surcharge where the effect of line surcharge is reversed in the process.

\section{Nomenclature} $x:$

$x_{F_{i}}:$
$F_{i}:$

The resultant lateral force in failure

$H: \quad$ surface $\quad$ Height of wall (m)

$K_{\mathrm{a}}: \quad$ Active earth pressure coefficient

without surcharge (dimensionless)

$K_{\text {aq }}$ : Coefficient of active pressure from the

surcharge (dimensionless)

$K_{\mathrm{as}}$ : $\quad$ Active earth pressure coefficient with

the effect of surcharge (dimensionless)

$P_{\mathrm{a}}$ : $\quad$ Active earth pressure without surcharge $(\mathrm{kN} / \mathrm{m})$

$P_{\text {aq }}: \quad$ Resultant lateral earth pressure from the surcharge $(\mathrm{kN} / \mathrm{m})$

$P_{\mathrm{as}}=P_{\mathrm{a}_{\text {surcharge }}}$ : Active earth pressure with the effect of surcharge $(\mathrm{kN} / \mathrm{m})$

$P_{i}: \quad$ Active pressure on wall in the $i$ th wedge

$q: \quad \quad$ Linear surcharge $(\mathrm{kN} / \mathrm{m})$

$W_{i}: \quad$ Weight of $i$ th slice $(\mathrm{kN})$.

\section{Greek Letters}

$\beta$ : Angle of failure wedge $\left({ }^{\circ}\right)$

$\beta_{1}$ : Angle of failure wedge without surcharge $\left({ }^{\circ}\right)$

$\beta_{2}$ : Angle of failure wedge on the location of the effect of surcharge $\left(^{\circ}\right)$

$\beta_{3}$ : Angle of failure wedge with the effect of surcharge $\left(^{\circ}\right)$

$\beta_{i}$ : Angle of failure wedge in the $i$ th experimental wedge $\left({ }^{\circ}\right)$

$\gamma:$ Total unit weight $\left(\mathrm{kN} / \mathrm{m}^{3}\right)$

$\delta$ : Friction angle between wall and backfill soil $\left({ }^{\circ}\right)$

$\phi$ : Angle of internal friction of soil $\left(^{\circ}\right)$.

\section{Conflicts of Interest}

The authors declare that they have no conflicts of interest.

\section{References}

[1] C. A. Coulomb, Essai sur une application des règles de maximis et minimis a quelques Problèmes de statique relatifs a l' architeture, 
Mémoires de savants étrangers de l' Académie des Sciences de Paris, 1773.

[2] W. J. M. Rankine, "On the mathematical theory of the stability of earthwork and masonry," Proceedings of Royal Society, vol. 8, pp. $69-87,1857$.

[3] J. V. Boussinesq, Application des Potentiels â L'Etude de L'Équilibre et du Mouvement des Solides Élastiques, GauthierVillars, Paris, France, 1885.

[4] B. M. Das, Principles of Soil Dynamics, PWS-Kent, Boston, Mass, USA, 1992.

[5] E. Gerber, Untersuchungen uber die Druckverteilung im orlich belasteten sand, Technische Hochscule, Zürich, Switzerland, 1929.

[6] M. G. Spangler, "Horizental pressure on retaining walls due to concentrated surface loads," Iowa State University Engineering Experiment Station, Bulletin, no 140, 1938.

[7] B. Misra, "Lateral pressures on retaining walls due to loads on surface of granular backfill," Soils and Foundations, vol. 20, no. 2, pp. 31-44, 1980.

[8] R. Jarquio, "Total lateral surcharge pressure due to strip load," Journal of the Geotechnical Engineering Division. ASCE, vol. 107, no. 10, pp. 1424-1428, 1981.

[9] E. Motta, "Generalized coulomb active-earth pressure for distanced surcharge," Journal of Geotechnical Engineering, vol. 120, no. 6, pp. 1072-1079, 1994.

[10] S. Caltabino, E. Cascone, and M. Maugeri, Seismic Stability of Retaining Walls with Surcharge, Faculty of Civil Engineering, University of Catania, Catania, Italy, 2000.

[11] S. Okabe, "General theory of earth pressures," Journal of the Japan Society of Civil Engineering, vol. 12, no. 1, 1926.

[12] N. Mononobe and H. Matsuo, "On the determination of earth pressure during earthquakes," in Proceeding of the World Engineering Congress, vol. 9, pp. 179-187, Tokyo, Japan, 1929.

[13] M. Georgiadis and C. Anagnostopoulos, "Lateral pressure on sheet pile walls due to strip load," Journal of Geotechnical and Geoenvironmental Engineering, vol. 124, no. 1, pp. 95-98, 1998.

[14] J. S. Kim and R. M. Barker, "Effect of live load surcharge on retaining walls and abutments," Journal of Geotechnical and Geoenvironmental Engineering, vol. 128, no. 10, pp. 803-813, 2002.

[15] V. R. Greco, "Active earth thrust on cantilever walls in general conditions," Soils and Foundations, vol. 39, no. 6, pp. 65-78, 1999.

[16] V. R. Greco, "Pseudo-static analysis for earth thrust computations," Soils and Foundations, vol. 43, no. 2, pp. 135-138, 2003.

[17] V. R. Greco, "Active earth thrust by backfills subject to a line surchange," Canadian Geotechnical Journal, vol. 42, no. 5, pp. 1255-1263, 2005.

[18] V. R. Greco, "Lateral earth pressure due to backfill subject to a strip of surcharge," Geotechnical and Geological Engineering, vol. 24, no. 3, pp. 615-636, 2006.

[19] AASHTO, Interims: Standard Specifications for Highway Bridges, American Association of State Highway and Transportation Officials, Washington, DC, USA, 2007.

[20] USACE, "Stability Analysis of Concrete Structures," USACE. EM 1110-2-2100, 2005.

[21] Y. M. Cheng, "Seismic lateral earth pressure coefficients for C$\varphi$ soils by slip line method," Computers and Geotechnics, vol. 30, no. 8, pp. 661-670, 2003.
[22] B. M. Basha and P. K. Basudhar, "Pseudo static seismic stability analysis of reinforced soil structures," Geotechnical and Geological Engineering, vol. 28, no. 6, pp. 745-760, 2010.

[23] A. Ghanbari and M. Taheri, "An analytical method for calculating active earth pressure in reinforced retaining walls subject to a line surcharge," Geotextiles and Geomembranes, vol. 34, pp. 1-10, 2012.

[24] M. Ahmadabadi and A. Ghanbari, "New procedure for active earth pressure calculation in retaining walls with reinforced cohesive-frictional backfill," Geotextiles and Geomembranes, vol. 27, no. 6, pp. 456-463, 2009.

[25] Beton Kalendar, Verlag von Wihelm Ernest and Sohn, Munich, Germany, 2002. 


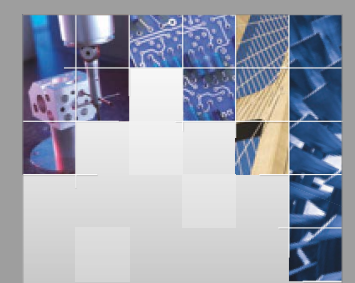

\section{Enfincering}
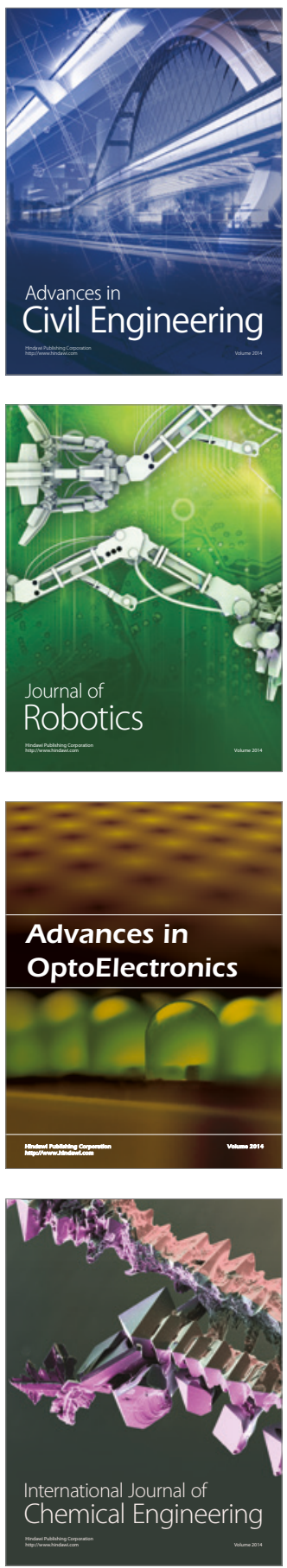

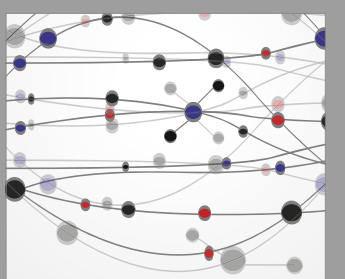

The Scientific World Journal

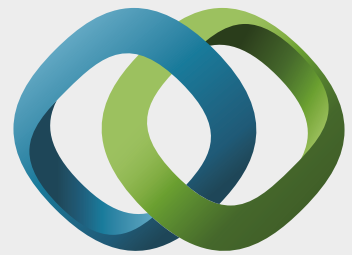

\section{Hindawi}

Submit your manuscripts at

https://www.hindawi.com
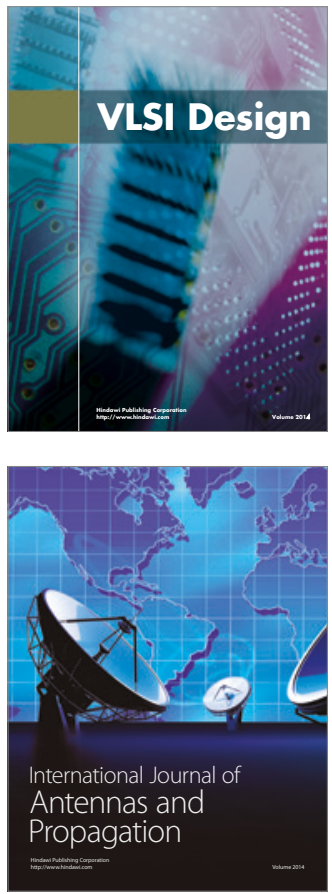

\section{Rotating}

Machinery
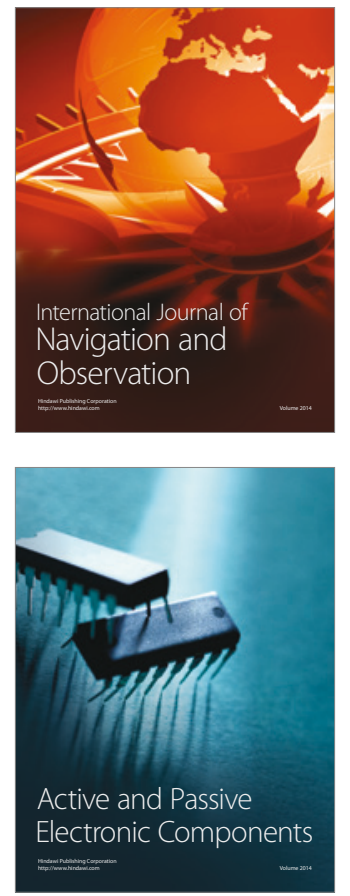
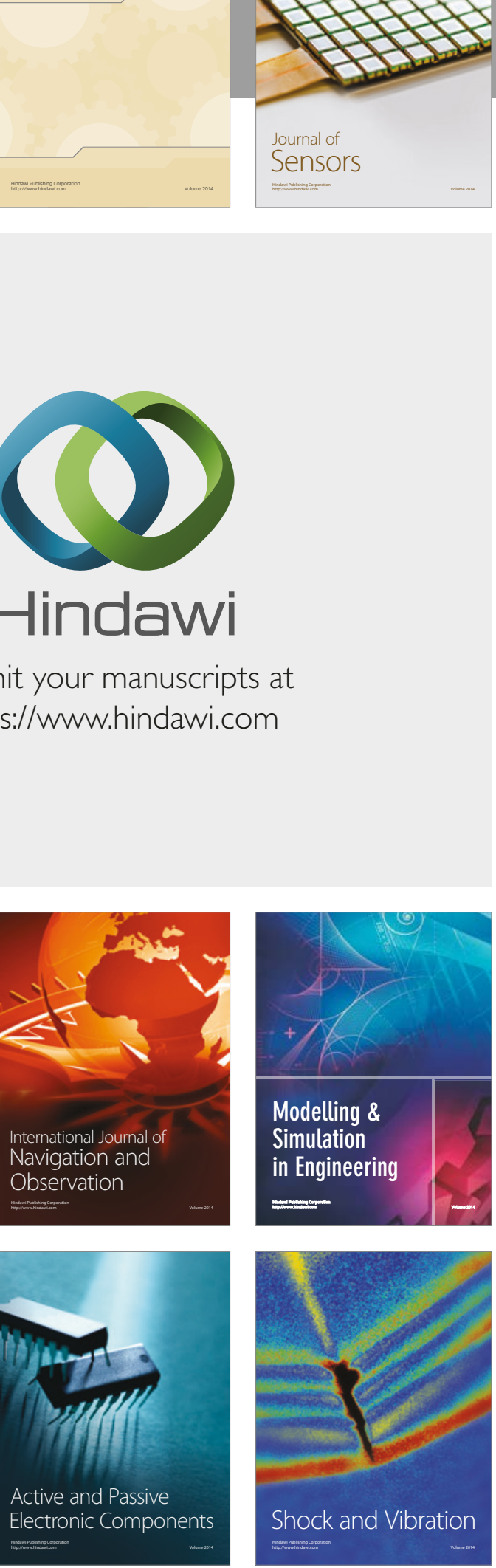
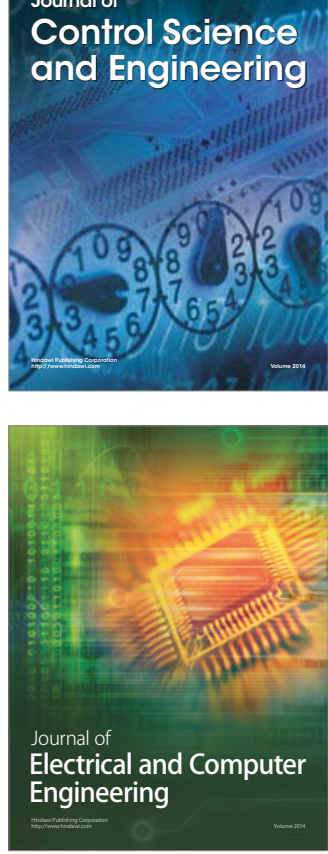

Distributed

Journal of

Control Science

and Engineering
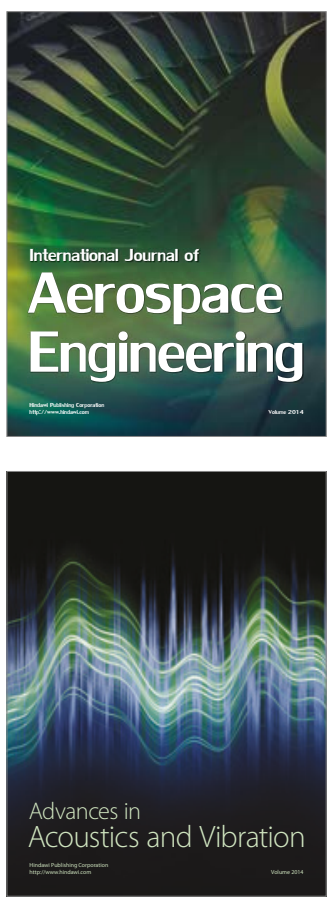

Sensor Networks 